\title{
PRODUÇÃO DO MELOEIRO SOB DIFERENTES LÂMINAS DE IRRIGAÇÃO E DOSES DE BIOESTIMULANTE NO SUBMÉDIO SÃO FRANCISCO
}

\section{PRODUCTION OF MELOEIRO TO DIFFERENT BLADES OF IRRIGATION AND DOSES OF BIOSTIMULANT IN SUBMEDIO SÃO FRANCISCO}

\author{
Welson Lima Simões ${ }^{1}$; José Sebastião Costa de Sousa ${ }^{2}$; Alessandra Monteiro Salviano ${ }^{3}$; \\ Marcelo Calgaro; ${ }^{4}$ Victor Hugo Freitas Gomes ${ }^{5}$
}

DOI: https://doi.org/10.31692/978-65-991061-7-0.421-426

\section{INTRODUÇÃO}

No Brasil, a região Nordeste é a principal produtora e exportadora de melão, com uma produtividade média de 29,01 t ha-1 (AGRIANUAL, 2017). Contudo, a sua produção é de uma maneira geral, muito aquém do seu potencial devido, principalmente, a interação de fatores, como o manejo inadequado e a falta da disponibilidade de água e de nutrientes no solo (ARAUJO et al., 2016).

Dessa forma, o manejo adequado da irrigação é uma ferramenta primordial no cultivo sustentável, tendo como intuito disponibilizar de forma racional a quantidade de água necessária à planta, possibilitando o seu desenvolvimento e crescimento durante o ciclo de cultivo (LIMA, et al. 2012). Além disso, a utilização de bioestimulantes tem-se tornado uma alternativa que pode viabilizar a suplementação de nutrientes em frutos e hortaliças, visto que essas substâncias promovem o aumento na quantidade de radicelas, melhorando assim a absorção de água e consequentemente de nutrientes pela planta (ELLI et al., 2016).

O objetivo deste trabalho foi avaliar o efeito de lâminas de irrigação e doses de bioestimulante nos parâmetros produtivos da cultura do meloeiro no Submédio São Francisco.

\section{FUNDAMENTAÇÃO TEÓRICA}

O Semiárido brasileiro, apresenta irregularidades nos atributos climáticos, dentre as quais estão os baixos índices pluviométricos e as altas taxas de evapotranspiração, que representam um grande entrave ao desenvolvimento agrícola. Assim, a irrigação é uma alternativa fundamental para superar a escassez de água e permitir ganhos na produção

\footnotetext{
${ }^{1}$ Engenheiro agrônomo, D.Sc. em Engenharia Agrícola, pesquisador da Embrapa Semiárido, welson.simoes@embrapa.br

${ }^{2}$ Engenheiro agrônomo, D.Sc. em Engenharia Agrícola, professor do IF Sertão Pernanbucano, sebastiao.costa@ifsertaope.edu.br

Engenheira agrônoma, D.Sc. em Fertilidade de Solos, pesquisadora da Embrapa Semiárido, alessandra.salviano@embrapa.br

${ }^{4}$ Engenheiro agrônomo, D.Sc. em Engenharia Agrícola, pesquisador da Embrapa Semiárido, marcelo.calgaro@embrapa.br

${ }^{5}$ Engenheiro agrônomo, Mestrando Engenharia Agrícola na UNIVASF, victorhfg@ @hotmail.com
} 
(VILAS BOAS et al., 2014).

Para a cultura do meloeiro é necessário a utilização de práticas de manejo que visem a otimização da aplicação de água por meio da lâmina de irrigação mais adequada em cada fase fenológica da mesma (MELO et al., 2011). Além disso, a utilização de bioestimulantes tem se mostrado uma ferramenta auxiliar para o aumento da produtividade das culturas. Esses compostos tem a capacidade de aumentar a absorção de água e de nutrientes, assegurando a resistência ao déficit hídrico, o que permite o melhor desenvolvimento das plantas em condições edafoclimáticas adversas (RUSSO \& BERLYN, 1990).

\section{METODOLOGIA}

O experimento foi executado no campo experimental do Instituto Federal de Educação Ciência e Tecnologia do Sertão Pernambucano, localizado na cidade de Petrolina, PE. De acordo com a classificação climática de Köppen o clima da região é do tipo BSwh', com temperaturas elevadas, chuvas escassas e mal distribuídas, concentrando-se nos meses de novembro a abril, com precipitação média anual em torno de $500 \mathrm{~mm}$ distribuída irregularmente ao longo do ano (LOPES et al, 2017).

Foi utilizada a cultivar de melão amarelo F1 Gladial, num espaçamento 2,0 m por 0,3 $\mathrm{m}$, com uso de mulching branco. O sistema de irrigação foi do tipo localizado por gotejamento superficial, com distribuição de mangueiras nas linhas de plantio, contendo emissores espaçados em $0,3 \mathrm{~m}$ e vazão de $2,0 \mathrm{~L} \mathrm{~h}^{-1}$. Realizou-se o cálculo da lâmina de irrigação com base no método de Penman Monteith a partir de dados climáticos coletados em uma estação meteorológica localizada próxima ao local do experimento. Os valores de Kc adotados nas diferentes fases de desenvolvimento do melão foram: Inicial=0,35; Vegetativa= 0,7 ; Frutificação= 1,0; e Maturação= 0,8, baseados nas recomendações de Miranda e Bleicher (2001).

O delineamento experimental utilizado foi o de blocos ao acaso em parcelas subdivididas, sendo as parcelas formadas por quatro lâminas de irrigação $(60 ; 80 ; 100 ; 120 \%$ da evapotranspiração da cultura - ETc) e as subparcelas constituídas por cinco doses do bioestimulante Citogrow $\left(0 ; 0,75 ; 1,5 ; 3,0\right.$ e 4,5 $\left.\mathrm{L} \mathrm{ha}^{-1}\right)$. O experimento foi realizado com quatro repetições, com seis plantas por subparcela.

Foram realizadas avaliações de produção coletando-se os dados a partir das seis plantas úteis da subparcela. Os parâmetros avaliados foram produtividade total (PT) e produtividade comercial (PC), obtidas através da pesagem total e seleção comercial com base na aparência e na massa individual dos frutos provenientes de cada parcela e, peso médio dos 
frutos (PMF), avaliado a partir da coleta, quantificação e pesagem.

Para a análise estatística, as médias dos resultados foram submetidas à análise estatística de regressão linear e quadrática a $5 \%$ de probabilidade.

\section{RESULTADOS E DISCUSSÕES}

Através da análise de variância observou-se interação significativa entre as lâminas de irrigação e doses de bioestimulante para os parâmetros número de frutos por $3,6 \mathrm{~m}^{2}$, peso médio do fruto e produtividade. Nas figuras 1A, 2A e 3A são apresentados os desdobramentos entre as doses e lâminas de irrigação para as características número de frutos por $3,6 \mathrm{~m}^{2}$, peso médio do fruto e produtividade, respectivamente.

Observa-se que as doses de 1,5; 3,0 e 4,5 $\mathrm{L} \mathrm{ha}^{-1}$ não influenciaram no número de frutos, conforme o aumento da lâmina de irrigação, com médias para essa característica de 12,$6 ; 12,3$ e 11,3 frutos por $3,6 \mathrm{~m}^{2}$, respectivamente. Por outro lado, houve o efeito das lâminas de irrigação no número de frutos nas doses de 0 e $0,75 \mathrm{~L} \mathrm{ha}^{-1}$. Nessas parcelas experimentais ambas as equações são polinomiais do primeiro grau, sendo que a dosagem de $0,75 \mathrm{~L} \mathrm{ha}^{-1}$, possui uma maior evolução no número de frutos, quando comparada com a dose de $0 \mathrm{~L} \mathrm{ha}^{-1}$.

$\mathrm{Na}$ interação lâmina de irrigação e dose de bioestimulante, observou-se que para a característica peso médio do fruto (Figura 1B) as equações ajustadas são polinomiais do segundo grau nas doses 0,$75 ; 1,5 ; 3,0$ e 4,5 $\mathrm{L} \mathrm{ha}^{-1}$, e as maiores médias estimadas para este atributo são encontradas nas lâminas de 88,52; 100,63; 92,76; e 93,03\% da ETc, com valores de peso médio do fruto correspondente a 1.812,04; 2.073,83; 1.918,0; e 1.936,60 g, respectivamente, para as parcelas experimentais nas doses de 0,$75 ; 1,5 ; 3,0$ e $4,5 \mathrm{~L} \mathrm{ha}^{-1}$. Por outro lado, no tratamento com a dose de $0 \mathrm{~L} \mathrm{ha}^{-1}$ a equação é uma regressão do primeiro grau, sendo que o peso do fruto aumentou conforme a lâmina de água. 
Figura 1 - A: Número de frutos; B: peso médio do fruto; e C: Produtividade de melão amarelo Gladial submetido a diferentes lâminas de irrigação e doses de bioestimulante no Submédio São Francisco.
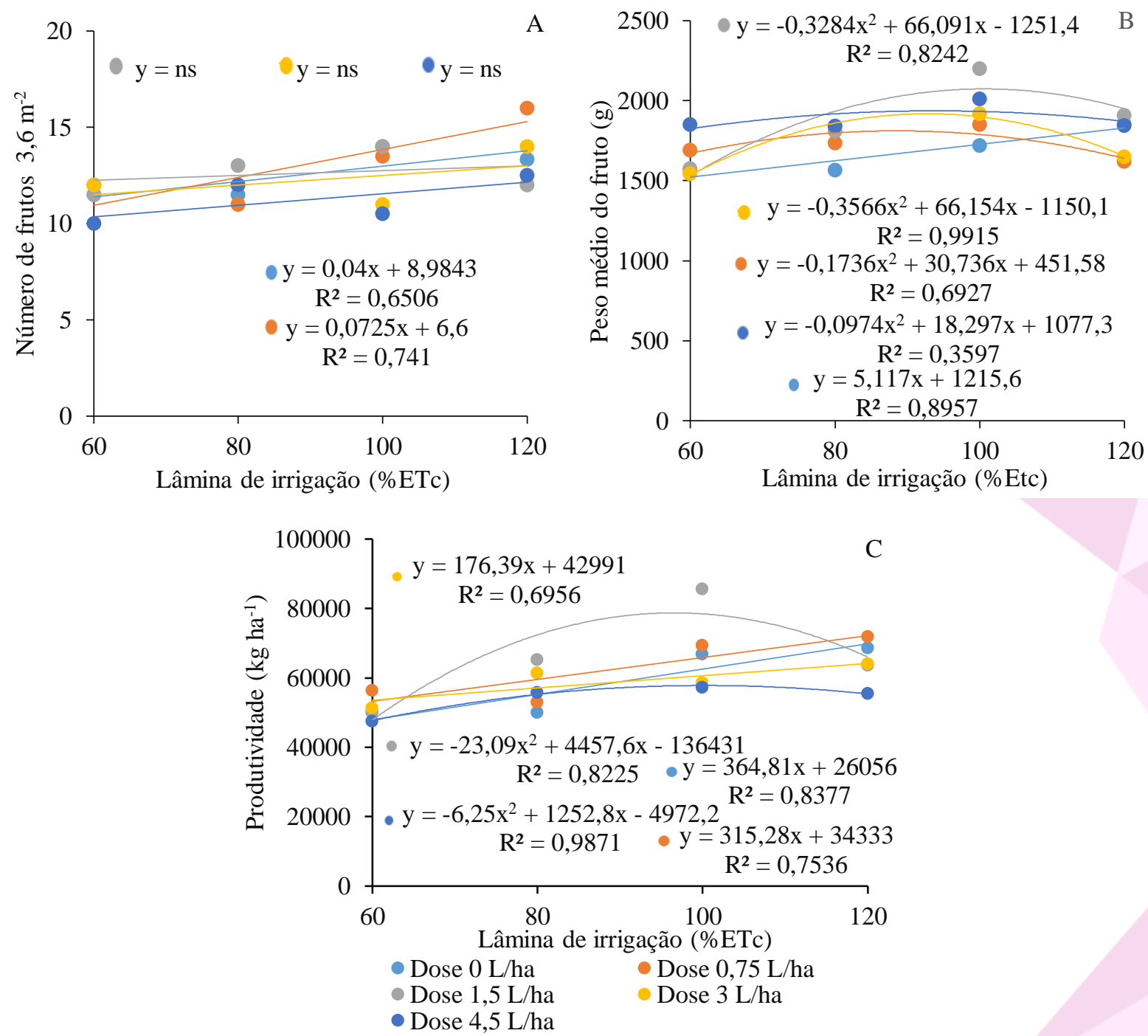

Para a produtividade (Figura 1C) as equações ajustadas são polinomiais do segundo grau nas dosagens: 1,5 e 4,5 $\mathrm{L} \mathrm{ha}^{-1}$ e os valores máximos de produtividade nessas parcelas são encontrados nas lâminas de 96,53 e 100,22\% da ETc, nessa ordem, com médias de 78.707,56 e $57.808,11 \mathrm{~kg} \mathrm{ha}^{-1}$, respectivamente. Para as concentrações $0 ; 0,75$ e 3,0 $\mathrm{L} \mathrm{ha}^{-1}$ de bioestimulante, as equações ajustadas são do primeiro grau, em que o aumento das lâminas de irrigação proporcionaram acréscimo na produtividade, sendo que a dose de $0,75 \mathrm{~L} \mathrm{ha}^{-1}$ apresentou tendência de crescimento maior do que as demais dosagens.

Ainda com relação aos resultados apresentados na figura 1B, é possível verificar que há maior resposta do produto para a lâmina próximo a 100\% da ETc. Além disso, na figura 1C pode-se notar que a dose de $1,5 \mathrm{~L} \mathrm{ha}^{-1}$ de bioestimulante proporcionou a maior produtividade, na lamina $96,53 \%$ da ETc. Esse efeito pode ser atribuído às funções dos 
reguladores vegetais presentes no bioestimulante. Segundo Kerbauy (2004), as auxinas promovem o crescimento de raízes laterais em virtude da síntese de hormônios e junto a citocinina são responsáveis pela divisão e alongamento celular, resultando no desenvolvimento de órgãos vegetais como caule e raiz. Essa característica permite que haja um maior crescimento e desenvolvimento da planta.

O efeito das lâminas de irrigação para o aumento no número de frutos, especialmente na dose de $0,75 \mathrm{~L} \mathrm{ha}^{-1}$, pode estar associado com o hormônio citocinina, visto que esse regulador atua na divisão celular, resultando no acréscimo do número de frutos (MARTINEAU et al., 1995; TAIZ \& ZEIGER, 2017). Por outro lado, o excesso de hormônios pode favorecer no desequilíbrio da quantidade de auxinas e giberelinas, ocasionando o decréscimo do crescimento das raízes adventícias, podendo reduzir no número de frutos (MACKINNON et al., 2010; KHAN et al., 2012), corroborando com os resultados encontrados nesse trabalho.

\section{CONCLUSÕES}

A concentração de 1,5 $\mathrm{L} \mathrm{ha}^{-1}$ de bioestimulante é a mais recomendada para o melão amarelo, visto que proporcionou maiores medias de produtividade e do peso médio do fruto.

O uso do bioestimulante contribui para a redução da lâmina de irrigação na cultura, visto que lâmina de irrigação estimada em 96,23\% da ETc proporcionou a maior produtividade.

\section{REFERÊNCIAS BIBLIOGRÁFICAS}

AGRIANUAL. Anuário da agricultura Brasileira. São Paulo: FNP: Consultoria Andamp; Comércio: 432 p. 2017.

ARAUJO, E. B. G.; SILVA SÁ, F. V.; OLIVEIRA, F. A.; SOUTO, L. S.; PAIVA, E. P.; SILVA, M. K. N.; BRITO, M. E. B. Crescimento inicial e tolerância de cultivares de meloeiro à salinidade da água. Revista Ambiente \& Água, v.11, n.2, p. 462, 2016.

ELLI, E. F; MONTEIRO, G. C.; KULCZYNSKI, S. M.; CARON, B. O.; SOUZA, V. Q. Potencial fisiológico de sementes de arroz tratadas com biorregulador vegetal. Revista Ciência Agronômica, v. 47, n. 2, p. 366-373, 2016.

KERBAUY G. B. 2004. Fisiologia vegetal. Rio de Janeiro: Guanabara Koogan. 452p.

KHAN, A. S.; AHMAD, B.; JASKANI M. J.; AHMAD, R.; MALIK, A. U. Foliar application of mixture of amino acids and seaweed (Ascophyllum nodosum) extract improve growth and physicochemical properties of grapes. International Journal of Agriculture and Biology, v.14, p.383-388, 2012. 
LIMA, M. E. et al. Desempenho do cultivo da berinjela em plantio direto submetida a diferentes lâminas de irrigação. Revista Brasileira de Engenharia Agrícola e Ambiental, v. 16, n. 6, p. 604-610, 2012.

LOPES, I.; GUIMARÃES, M. J. M.; MELO, J. M. DE; RAMOS, C. M. C. Balanço hídrico em função de regimes pluviométricos na região de Petrolina-PE. Revista Irriga, v.22, n.3, p.443-457, 2017.

MACKINNON, S.L.; HILTZ, D.; UGARTE, R.; CRAFT, C. A. 2010.Improved methods of analysis for betaines in Ascophyllum nodosum and its commercial seaweed extracts. Journal of Applied Phycology, v.22, p. 489-494, 2010

MARTINEAU, B.; SUMMERFELT, K. R.; ADAMS, D. F.; VERNA, J. W. Production of high solids tomatoes through molecular modification of levels of the plant growth regulator cytokinin. Nature Biotechnology, v.13, 250-255, 1995.

MELO, T. K.; MEDEIROS, J. F.; ESPÍNOLA SOBRINHO, J.; FIGUEIRÊDO, V. B.; PEREIRA, V. C.; CAMPOS, M. S. Evapotranspiração e produção do melão Gália irrigado com água de diferentes salinidades e adubação nitrogenada. Revista Brasileira de Engenharia Agrícola e Ambiental, v. 15, n. 12, p. 1235-1242, 2011.

MIRANDA, F. R.; BLEICHER, E. Evapotranspiração e coeficientes de cultivo e de irrigação para a cultura do melão (Cucumis melo L.) na região litorânea do Ceará. Fortaleza: Embrapa Agroindústria Tropical, 2001. 17 p.

RUSSO, R. O; BERLYN, G. P. The Use of Organic Biostimulants to Help Low Input Sustainable Agriculture. Journal of Sustainable Agriculture, 1, v.19-42, 1990

TAIZ, L.; ZEIGER, E. Fisiologia vegetal. 6. ed. Porto Alegre: Artmed, 2017. 858p.

VILAS BOAS, R. C.; CARVALHO, J. G.; PEREIRA, G. M.; SOUZA, R. J.; GAMA, G. B. N.; GARCIA, H. G.; ARAÚJO, R. S. A. Rendimento da cultura da cebola submetida a níveis de água e nitrogênio por gotejamento. Semina: Ciências Agrárias, v. 35, n. 2, p.633-646, 2014. 